\title{
Benefit finding and well-being in older adults: The utility of the General Benefit Finding Scale.
}

\author{
La búsqueda de beneficios y el bienestar de los adultos mayores: la utilidad de la Escala General de Beneficios
}

Tony Cassidy ${ }^{1 *}$, Ingrid Doyle ${ }^{2}$

\begin{abstract}
The research aim was to test the General Benefit Finding Scale (GBFS) in a cross-sectional survey of adults aged 55 years and older and to assess to what extent it relates to mental well-being, perceived social support, health and personality. Participants $(n=341)$ completed a questionnaire which included demographic questions, the GBFS, and measures of mental well-being, perceived social support, activity levels, and personality. Benefit finding was higher in older adults and correlated positively with mental well-being and perceived support. The impact of the psychosocial factors investigated on benefit finding levels was small (9.2\%) with mental well-being, sex and agreeableness being significant predictors. The study provides additional support for the use of the GBFS and suggests that perceived social support, particularly from friends, is especially important for older adults.

Resumen

El objetivo fue evaluar la Escala General de Beneficios (GBFS) en un estudio transversal de una muestra de adultos mayores de 55 años, y determinar en qué medida se relaciona con bienestar mental, apoyo social percibido, salud y personalidad. Los participantes $(n=341)$ completaron un cuestionario que incluía preguntas demográficas, GBFS y medidas de bienestar mental, apoyo social percibido, niveles de actividad y personalidad. La búsqueda de beneficios fue mayor en los adultos mayores que en los más jovenes, se correlacionó positivamente con bienestar mental y apoyo social percibido. Sin embargo, aunque significativo, el impacto de los factores psicosociales investigados en los niveles de beneficio de la búsqueda fue pequeño (9.2\%) con bienestar mental, sexo y amabilidad son predictores significativos. El estudio proporciona apoyo adicional para el uso de la GBFS y sugiere que el apoyo social percibido, particularmente de los amigos, es especialmente importante para los adultos mayores.
\end{abstract}

Keywords

benefit finding; age; mental well-being; support; personality

Palabras Clave

búsqueda de beneficios; edad; bienestar mental; apoyo; personalidad

${ }^{1}$ Child and Family Health Psychology - Coleraine Campus.

${ }^{2}$ Ulster University

*Corresponding author: t.cassidy@ulster.ac.uk

Manuscript received 14-02-2018; revised 13-04-2018; accepted 07-05-2018.

\section{Introduction}

Health has been described as "not merely the absence of disease or infirmity" but as a "state of complete physical, mental and social well-being" (WHO, 1947) with a steady acceptance that national subjective well-being scores tend to be strongly correlated with objective health indicators (Morrison \& Bennett, 2012), reflecting the quality of life in a society. They have been included in recent United Nations Development Program reports and will also be considered as part of British policy in the future (Diener,
Oishi, \& Lucas, 2015).

Over the past twenty years or so, attention has shifted from an emphasis on research into stressors and coping to looking at "adversarial growth" (Tennen \& Affleck, 2002) or "benefit finding" (as cited in Cassidy, McLaughlin, \& Giles, 2014, p. 268). There is increasing evidence that some people can actually derive some benefit in the face of adversity. Links have been found between benefit finding and health (Helgeson, Reynolds, \& Tomich, 2006) in those suffering chronic or life threatening diseases. Furthermore, benefit finding in times of trauma has been 
linked to lower levels of depression and higher levels of well-being (Affleck, Tennen, Croog, \& Levine, 1987; Bower, Kemeny, Taylor, \& Fahey, 1998; McGregor \& Antoni, 2009).

Benefit finding refers to an individual's perceptions that they have derived some positive effects from challenging experiences, including illness, and traumatic events. It is generally defined as consisting of a number of dimensions including greater acceptance of one's life situation, a strengthening of family bonds experience of growing psychologically as a person, affirmation of relationships, a sense of greater empathy with others, and a reappraisal of one's life and reprioritization of goals (Cassidy et al., 2014; Helgeson et al., 2006).

Social and psychological resources have been found to mediate the relationship between stressors and benefit finding (Cassidy et al., 2014), but most research has focused on those who have experienced serious trauma, or serious or chronic disease. The 28-item General Benefit Finding Scale (GBFS) was devised Cassidy et al. (2014) to measure benefit finding levels in response to everyday hassles and provide a step in the direction of a deeper understanding of the resources required for preventative interventions to improve positive psychological health (Cassidy et al., 2014).

Although the sample in this study was impressively large, it was a very specific cohort - of university students with a mean age of 23.4 years, and the authors suggest the measures need to be tested in other populations. More people in the Western world are living longer (and birth rates are falling). In Ireland alone it is predicted that the number of people over 65 years will double over the next 30 years and those over the age of 80 will quadruple (Department of Health, 2015). This demographic change, described as a "ticking time bomb" (Wheatley, 2013), is not only likely to have financial consequences, but more attention will be required to ensure that individuals age in as healthy, productive and happy a way as possible.

In terms of positive psychological health for all ages, factors such as social support, mental well-being and physical activity are important correlates. Social support has been related to lower levels of anxiety, mortality and depression with the personality traits of extraversion, neuroticism and agreeableness more likely to be related to perceived social support (Allemand, Schaffhuser, \& Martin, 2015). Personality traits, particularly conscientiousness and neuroticism, are associated with health and well-being (Deary, Weiss, \& Batty, 2010; Goodwin \& Friedman, 2006; Weiss, Bates, \& Luciano, 2008).

The relationship between benefit finding and stress is far from consistent (Kleim \& Ehlers, 2009) and indeed, the authors of the GBFS found that age, amongst other things, may be a factor in determining the linearity of the relationship. The trajectory of well-being in older adults was found to follow an inverted U-shape (Baird,
Lucas, \& Donnellan, 2010), with a similar trajectory, associated with self-reported health status and chronic illness, also recently found between optimism and age (Chopik, Kim, \& Smith, 2015).

Resilience and an active engagement in life are amongst a range of psychosocial factors considered to be important for healthy ageing (Hicks \& Conner, 2014). Loss of a partner or retirement can result in loneliness, a risk factor for Alzheimer's disease (Wilson et al., 2007) and changes in social interaction, such as social engagement or emotional support, have repercussions on levels of life satisfaction (Huxhold, Fiori, \& Windsor, 2013). As age increases, so does the propensity for chronic disease, disability, cognitive decline, and bereavement, with consequent risks to positive health (McKee \& Schüz, 2015). Key risks for health in older adults include social isolation, reduced physical activity, and poor mental health (WHO, 2012). In contrast, social integration / support, physical activity, personality, and benefit finding are protective in terms of mental health (Cassidy et al., 2014).

The aim of this study was to assess if the factor structure of the GBFS would be evident in a sample of older adults in response to everyday stressors, and to explore if benefit finding would be related to well-being, support, personality and physical activity.

\section{Method}

\subsection{Sample and Procedures}

Following ethical approval, permission was granted to recruit adults, aged 55 years and older, living in the community and of good cognitive health. This allowed assessment of the potential effect of ill or deteriorating health/physical activity on benefit finding levels. Quantitative data collection consisted of an online, selfadministered questionnaire. To protect participants' identities, no identifying information was present in either case.

Power analysis using $\mathrm{G}^{*}$ Power suggested for a medium effect size and power of .95 that a minimum of 138 participants was required. To allow for non-responders, a sample size of approximately 200 participants were targeted. Participants were recruited by various measures. The Aer Lingus Active Retirement group (over 3000 members), was approached and agreed to host the survey. The survey was also hosted on a number of other Facebook pages and various community members were asked to distribute the link to anybody aged 55 years or older. Paper-based surveys were distributed locally and to relatives and friends of the researcher. All were returned anonymously to her address. All participants were provided with an information sheet and advised that their participation was entirely voluntary and that their responses would be kept confidential. Completion of the questionnaire was taken as implicit consent. 
Table 1

Items, factor loadings and psychometric data for the new scale

\begin{tabular}{|c|c|}
\hline Total \% Variance $=67.1$ & Factor loadings \\
\hline \multicolumn{2}{|l|}{ Acceptance: $\alpha=.79$ Eigenvalue $=4.10 \%$ Variance $=14.7$} \\
\hline Led me to be more accepting of things. & .66 \\
\hline Taught me how to adjust to things I cannot change. & .71 \\
\hline Helped me take things as they come. & .75 \\
\hline Given me a more realistic set of expectations. & .61 \\
\hline Taught me to be patient. & .61 \\
\hline \multicolumn{2}{|l|}{ Family bonds: $\alpha=.85$ Eigenvalue $=3.45 \%$ Variance $=12.3$} \\
\hline Brought my family closer together. & .78 \\
\hline Made me more sensitive to family issues. & .68 \\
\hline Helped me appreciate my family more. & .82 \\
\hline Made me more aware of what my family means to me. & .75 \\
\hline \multicolumn{2}{|l|}{ Growth: $\alpha=.90$ Eigenvalue $=3.43 \%$ Variance $=12.2$} \\
\hline Made me a more effective person. & .67 \\
\hline Taught me how to cope more effectively. & .77 \\
\hline Helped me become a stronger person. & .80 \\
\hline Taught me I can handle most things. & .79 \\
\hline Led me to deal better with problems. & .74 \\
\hline Helped me to grow emotionally and spiritually. & .69 \\
\hline \multicolumn{2}{|l|}{ Relationships: $\alpha=.72$ Eigenvalue $=3.01 \%$ Variance $=10.7$} \\
\hline Helped me become more aware of the support available from others. & .69 \\
\hline Helped me realize who my real friends are. & .70 \\
\hline Led me to feel more positive about others. & .60 \\
\hline Led me to meet people who have become some of my best friends. & .42 \\
\hline \multicolumn{2}{|l|}{ Empathy: $\alpha=.86$ Eigenvalue $=2.75 \%$ Variance $=9.8$} \\
\hline Made me more compassionate to those in similar situations. & .81 \\
\hline Made me more sensitive to the needs of others. & .73 \\
\hline Made me care more about others. & .54 \\
\hline Made me closer to people I care about. & .45 \\
\hline Taught me that everyone has a right to be valued. & .56 \\
\hline \multicolumn{2}{|l|}{ Reprioritisation: $\alpha=.90$ Eigenvalue $=2.04 \%$ Variance $=7.3$} \\
\hline Led me to place less emphasis on material things. & .76 \\
\hline Led me to live my life more simply. & .81 \\
\hline Led me to change my priorities in life. & .83 \\
\hline Helped me become more focused on real priorities. & .75 \\
\hline
\end{tabular}

A total of 352 responses were received - 19 were paperbased and the remainder online. No differences were observed between the online and paper-based responses. Eleven participants had missing data and were removed from the dataset leaving a total of 341 participants (241 females and 100 males). Ages ranged from 55 years to 83 years with a mean age of $62.7(\mathrm{sd}=6.6)$. Over two thirds $(68.2 \%)$ were married, $12.5 \%$ were single and the remainder were widowed or divorced $(9.9 \%$ and $9.3 \%$ respectively). The vast majority $(99.4 \%)$ lived in their own home.

\subsection{Measures}

Benefit Finding: The 28-item General Benefit Finding Scale (GBFS), which incorporates six different factors, was used to ascertain levels of benefit finding in relation to general life stress. The authors found it to have good internal reliability reporting Cronbach's Alpha for the six factors as follows - acceptance $(\alpha=.86)$, family bonds $(\alpha=.76)$, personal growth $(\alpha=.81)$, relationships $(\alpha=.83)$, empathy $(\alpha=.80)$ and reprioritisation $(\alpha=.82)$ (Cassidy et al., 2014). Cronbach's Alphas in the current data are shown in Table 1.

Personality: Big Five Personality constructs were assessed using the BFI-10 - short form (Rammstedt \& John, 2007). This short, one minute, 10-item measure has been found to have significant levels of validity and reliability with mean intercorrelations when tested on two different cultures (Rammstedt \& John, 2007) of .11 and mean Cronbach's Alpha reported as $(\alpha=.75)$. 
Table 2

Psychometric criteria and scale performance

\begin{tabular}{lll}
\hline Property & Criteria for acceptability & Performance of scale \\
\hline Item analysis $/$ & All items should have factor loadings & Factor loadings range 0.45 \\
reduction & $>0.30$ & to 0.83 \\
& Missing data $<5 \%$ & No missing data \\
& Inter-item correlations $<0.75$ & Inter-item correlations range 0.35 to 0.68 \\
& Item total correlations $\geq 0.25$ & Item total correlations range 0.45 to 0.76 \\
& Maximum endorsement frequency $<80 \%$ Maximum endorsement frequency $=72.3 \%$ \\
& Minimum adjacent endorsement $>10 \%$ & Minimum adjacent endorsement $=18.9 \%$ \\
Acceptability & Skewness values $<1$ & Maximum skewness 0.89 \\
& Missing data $<5 \%$ & No missing data \\
Reliability & Cronbach's Alpha $>0.70$ & Cronbach's Alphas range 0.72 to 0.90 \\
& Item total correlations $\geq 0.20$ & Item total correlations range 0.45 to 0.76 \\
\hline \hline
\end{tabular}

Table 3

Differences between males and females and between current sample and original sample on benefitfinding

\begin{tabular}{lllll}
\hline Variable & $\begin{array}{l}\text { Male } \\
(\boldsymbol{n}=\mathbf{1 0 0}) \\
\text { Mean }(\mathbf{S d})\end{array}$ & $\begin{array}{l}\text { Female } \\
(\boldsymbol{n}=\mathbf{2 4 1}) \\
\text { Mean }(\mathbf{S d})\end{array}$ & $\begin{array}{l}\text { Current } \\
\text { Sample } \\
\text { Mean }(\boldsymbol{M}+\boldsymbol{F})\end{array}$ & $\begin{array}{l}\text { Original } \\
\text { Sample } \\
\text { Mean }(\boldsymbol{M}+\boldsymbol{F})\end{array}$ \\
\hline Benefit-finding & $20.99(3.77)$ & $22.13(3.44)$ & 3.63 & 3.2 \\
Empathy & $3.78(0.84)$ & $4.05(0.69)$ & 3.97 & 3.2 \\
Family Bonds & $3.54(0.87)$ & $3.76(0.88)$ & 3.70 & 3.4 \\
Relationships & $3.27(0.77)$ & $3.50(0.71)$ & 3.43 & 3.1 \\
Acceptance & $3.39(0.75)$ & $3.47(0.67)$ & 3.45 & 3.3 \\
Growth & $3.49(0.77)$ & $3.64(0.77)$ & 3.60 & 3.1 \\
Reprioritisation & $3.53(0.98)$ & $3.71(0.91)$ & 3.65 & 3.0 \\
\hline
\end{tabular}

In this data the Cronbach Alphas were: extraversion $(\alpha=0.82)$, conscientiousness $(\alpha=0.76)$, neuroticism $(\alpha=$ $0.73)$, openness $(\alpha=0.71)$, and agreeableness $(\alpha=0.70)$.

Social Support: The short version of the Lubben Social Network Scale (LSNS-6; J. E. Lubben, 1988) is a six item measure which assesses the size, type, closeness and frequency of social contacts in adults thereby measuring levels of social isolation. The scale differentiates between family and non-family but does not differentiate between friends and neighbours. It was constructed initially for use with older adults (aged 65 years and above) although it has been successfully utilized in both research and practice settings for adults of all ages, some as young as 18 (Honeycutt, Nasser, Banner, Mapp, \& DuPont, 2008; Howarter \& Bennett, 2013; McConkey \& Leavey, 2013; Momtaz, Haron, Ibrahim, \& Hamid, 2014). High levels of reliability and consistency have been reported (J. Lubben et al., 2006) with Cronbach's Alpha values ranging from $\alpha=0.84-0.89$ for the family subscale and $(\alpha=0.80-0.82)$ for the friends subscale. In the current study Cronbach Alphas were friends $(\alpha=0.84)$ and family $(\alpha=0.81)$.
Activity Levels: Level and intensity of participants' activity levels were assessed using the Rapid Assessment of Physical Activity (RAPA; Topolski et al., 2006). This short 9-item measure was devised using a cohort of older adults aged 51-92. With test-retest reliability scores ranging between $(\alpha=0.65)$ (Vega-López, Chavez, Farr, $\&$ Ainsworth, 2014) and ( $\alpha=0.67)$ (Silva, Queirós, Alvarelhão, \& Rocha, 2014), it has been deemed to be a valid and easy-to-use measure of physical activity in older adults (Topolski et al., 2006). In the current data the Cronbach's Alpha was .94.

Mental Well-Being: The Warwick-Edinburgh Mental Well-Being Scale (WEMWBS) to assess mental wellbeing has been found to be psychometrically robust and suitable for use for those over 16 years of age (Tennant et al., 2007). In an effort to reduce the overall number of questions, the short 7 -item version was used (SWEMWBS). This version has been found to be unidimensional and largely free of bias, and the level of reliability has been reported as $(\alpha=0.85)$ (Stewart-Brown et al., 2009). The Cronbach Alpha in the current study was .86 . 
Demographic questions: The demographic questions included gender, age, and relationship status.

Ethical issues: Following careful consideration, the University of Ulster Filter Committee deemed that any ethical issues had been identified and addressed and were not a cause for concern.

Statistical analysis: Confirmatory factor analysis using the AMOS programme was used to test the factor structure of the scale. One-sample t-tests were used to compare the mean scores in this sample to the means in the original study. Hierarchical Multiple Regression Analysis (HMRA) was used to test the partial correlations between benefit finding, well-being, support and physical activity.

\section{Results}

The first aim of this study was to test the psychometric properties of the General Benefit Finding Scale (GBFS) in an older adult population. The scale was initially developed and tested in a student sample. To test the factor structure a Confirmatory Factor Analysis was applied using the Amos programme on SPSS. In testing model fit there is still some debate about cut off values for goodness of fit. For this study we used the review by Hooper, Coughlan, and Mullen (2008), and specifically the following cut offs. A non-significant chi-square or a chi-square to degrees of freedom ratio of 3:1 or less (CMin/Df), a Comparative Fit Index (CFI) of .95 or greater, an Incremental Fit Index (IFI) of .95 or greater, a Root Mean Square Error of Approximation (RMSEA) of .08 or less (ideally as close to .05 as possible), and a Standardised Root Mean Square Residual (SRMR) of less than .08. The initial model had a $\chi^{2}$ of 50.39 with 8 degrees of freedom $(p<.001)$, with a CFI $=.95$, an IFI $=.95$, a RMSEA $=.12$, and a SRMR $=.03$. The modification index indicated that the model fit could be improved by allowing reprioritization to correlate with both acceptance and relationships. The new model thus produced had a $\chi^{2}$ of 14.95 with 6 degrees of freedom $(p<.05)$, CFI $=.99$, an IFI $=.99$, a RMSEA $=.06$ (CI: $.02-.08)$, and SRMR $=.02$. Although the $\chi^{2}$ is significant this may be because of the large sample size and the relative / normed $\chi^{2}\left(\chi^{2}: \mathrm{df}\right)$ is 2.4:1 which is lower than the accepted cut off of 3:1 recommended by Kline et al. (2005). Overall the model is a good fit.

We used the set of criteria proposed by Lamping et al. (2002) and summarised by Smith et al. (2005) to set out some of the psychometric properties of the data (see Table 2). The data used in this study was based on a cross sectional survey so test- retest reliability was not tested. However, the items and factors perform well on all the other dimensions as shown in Table 2.

The next aim was to compare levels of benefit finding in the current sample with those in the original sample; one-sample t-tests were performed on benefit-finding in general, and on each of the individual variables within benefit-finding. Contrary to expectation, on all tests, the current sample scored significantly higher than the original sample $(p=0.001)$ - see Table 3 for details. Benefit finding in general, $\mathrm{t}(340)=13.4, p<.001$, growth, $\mathrm{t}(340)=11.9, p<.001)$, reprioritisation, $\mathrm{t}(340)=12.99$, $p<.001$, empathy, t $(340)=19.07, p<.001$, family bonds, $\mathrm{t}(340)=6.19, p<.001$, acceptance, $\mathrm{t}(340)=3.89, p<$ .001 and relationships, $\mathrm{t}(340)=8.35, p<.001$.

Next, two separate hierarchical multiple regression analyses (HMRA) were undertaken to explore partial correlations between the study variables. In the first analysis well-being was entered as the dependent variable (Table 4). On the first step age and sex were entered as predictor variables. On the second step the personality dimensions (extraversion, agreeableness, conscientiousness, neuroticism, and openness to experience) were entered. On the third step support was added and on the fourth step we entered physical activity. Finally, benefit finding was entered. Overall the model accounted for a small but significant percentage of variance in well-being $\left(R^{2}=.196, \mathrm{~F}(10,330)=8.047\right.$, $p<.001)$. The individual significant partial correlations were extraversion $(\beta=.142, p<.01$, neuroticism $(\beta=-.153, p<.01)$, support from friends $(\beta=.348$, $p<.001)$, and benefit finding $(\beta=.141, p<.01)$.

The second HMRA followed the same format except that well-being was removed and benefit finding entered as the dependent variable (Table5). Again, the model accounted for a small but significant percentage of variance in benefit finding $\left(R^{2}=.092, F(9,331)=4.913, p<.01\right)$. The individual significant partial correlations were sex $(\beta=.145, p<.01)$, agreeableness $(\beta=-.172, p<.01)$, and support from friends $(\beta=.189, p<.001)$. Females scored significantly higher on benefit finding than males $(\mathrm{t}(339)=2.699, p<.01)$.

\section{Discussion}

At the outset, it was expected that benefit finding levels would be lower in the older sample, given the adverse health consequences and sometimes negative changes in social interaction that aging can bring. Contrary to expectations, the older adults in this study scored higher than the university student sample on general benefit finding levels and on every individual element of the benefit finding scale. Both a curvilinear and linear relationship between post-traumatic stress disorder and post-traumatic growth was found in a recent metaanalysis by Shakespeare-Finch and Lurie-Beck (2014), with the type of event and the age of the individual believed to possibly affect the linearity of the relationship.

Longitudinal research has found that aging effects may differ depending on the cohort examined (Jivraj, Nazroo, Vanhoutte, \& Chandola, 2014; Tampubolon, 2015). Recent findings have noted generational differ- 
Table 4

Partial correlations with well-being from Hierarchical Multiple Regression

\begin{tabular}{|c|c|c|c|c|}
\hline & B & SE B & $\beta$ & $P$ \\
\hline \multicolumn{5}{|c|}{$R^{2}=.007, \mathrm{~F}(2,338)=1.211, p=.299$} \\
\hline Sex & -.577 & .494 & -.063 & .244 \\
\hline Age & .034 & .034 & .054 & .324 \\
\hline \multicolumn{5}{|c|}{$R^{2}=.079, \mathrm{~F}(5,333)=5.762, p<.001$} \\
\hline Sex & -.433 & .488 & -.047 & .376 \\
\hline Age & .031 & .034 & .049 & .364 \\
\hline Extraversion & .271 & .118 & .129 & .022 \\
\hline Agreeableness & .193 & .129 & .088 & .135 \\
\hline Conscientiousness & .095 & .124 & .047 & .447 \\
\hline Neuroticism & -.390 & .127 & -.170 & .002 \\
\hline Openness & -.118 & .116 & -.059 & .309 \\
\hline \multicolumn{5}{|c|}{$R^{2}=.082, \mathrm{~F}(1,332)=32.594, p<.001$} \\
\hline Sex & -.585 & .467 & -.064 & .211 \\
\hline Age & .029 & .032 & .047 & .361 \\
\hline Extraversion & .303 & .113 & .145 & .008 \\
\hline Agreeableness & .358 & .126 & .164 & .005 \\
\hline Conscientiousness & .254 & .122 & .126 & .038 \\
\hline Neuroticism & -.375 & .121 & -.163 & .002 \\
\hline Openness & -.033 & .112 & -.016 & .769 \\
\hline Support from friends & .154 & .027 & .324 & .000 \\
\hline \multicolumn{5}{|c|}{$R^{2}=.01, \mathrm{~F}(1,331)=3.892, p<.05$} \\
\hline Sex & -.521 & .466 & -.057 & .265 \\
\hline Age & .032 & .032 & .051 & .321 \\
\hline Extraversion & .285 & .113 & .136 & .012 \\
\hline Agreeableness & .293 & .130 & .134 & .025 \\
\hline Conscientiousness & .177 & .127 & .088 & .165 \\
\hline Neuroticism & -.368 & .120 & -.160 & .002 \\
\hline Openness & -.078 & .114 & -.039 & .491 \\
\hline Support & .178 & .029 & .375 & .000 \\
\hline Physical activity & .107 & .054 & .144 & .048 \\
\hline \multicolumn{5}{|c|}{$R^{2}=.018, \mathrm{~F}(1,330)=7.558, p<.01$} \\
\hline Sex & -.707 & .467 & -.078 & .131 \\
\hline Age & .026 & .032 & .042 & .407 \\
\hline Extraversion & .297 & .112 & .142 & .008 \\
\hline Agreeableness & .241 & .130 & .110 & .065 \\
\hline Conscientiousness & .180 & .126 & .089 & .155 \\
\hline Neuroticism & -.374 & .119 & -.163 & .002 \\
\hline Openness & -.075 & .113 & -.037 & .507 \\
\hline Support & .165 & .030 & .348 & .000 \\
\hline Physical activity & .098 & .054 & .133 & .068 \\
\hline Benefit finding & .982 & .357 & .141 & .006 \\
\hline
\end{tabular}

ences, with increased dissatisfaction and lower subjective well-being in younger cohorts (Baird et al., 2010). Those who participated in this study were aged 55 years and older and therefore from the Baby Boomer generation. Recent evidence has shown that Baby Boomers are significantly more likely to rate their health as "excellent" than those in the following Generation X cohort (Pilkington, Taylor, Hugo, \& Wittert, 2014) and that the greater the emotional support provided by both parents of Baby Boomers, the more positive the impact on their emotional well-being in later life (Poon \& Knight, 2013). The university students studied in the Cassidy et al. (2014) research, however, were from the Millennial generation, recently described as being "highly optimistic" and living in an age of "soaring expectations and crushing realities" (Twenge, 2014, p3) 
Table 5

Partial correlations with benefit finding from hierarchical regression analysis

\begin{tabular}{|c|c|c|c|c|}
\hline & B & SE B & $\beta$ & $P$ \\
\hline \multicolumn{5}{|c|}{$R^{2}=.028, \mathrm{~F}(2,338)=4.913, p<.01$} \\
\hline Sex & .193 & .070 & .148 & .006 \\
\hline Age & .008 & .005 & .085 & .114 \\
\hline \multicolumn{5}{|c|}{$R^{2}=.019, \mathrm{~F}(5,333)=1.362, p=.238$} \\
\hline Sex & .195 & .071 & .149 & .007 \\
\hline Age & .005 & .005 & .060 & .272 \\
\hline Extraversion & -.014 & .017 & -.045 & .432 \\
\hline Agreeableness & .048 & .019 & .152 & .012 \\
\hline Conscientiousness & -.008 & .018 & -.026 & .675 \\
\hline Neuroticism & .005 & .019 & .015 & .788 \\
\hline Openness & -.006 & .017 & -.020 & .735 \\
\hline \multicolumn{5}{|c|}{$R^{2}=.020, \mathrm{~F}(1,332)=7.008, p<.01$} \\
\hline Sex & .184 & .071 & .141 & .010 \\
\hline Age & .005 & .005 & .059 & .275 \\
\hline Extraversion & -.011 & .017 & -.038 & .510 \\
\hline Agreeableness & .059 & .019 & .189 & .002 \\
\hline Conscientiousness & .004 & .019 & .012 & .846 \\
\hline Neuroticism & .006 & .018 & .019 & .740 \\
\hline Openness & .000 & .017 & .001 & .988 \\
\hline Support from friends & .011 & .004 & .159 & .009 \\
\hline \multicolumn{5}{|c|}{$R^{2}=.003, \mathrm{~F}(1,331)=1.203, p=.273$} \\
\hline Sex & .190 & .071 & .145 & .008 \\
\hline Age & .006 & .005 & .061 & .258 \\
\hline Extraversion & -.013 & .017 & -.043 & .454 \\
\hline Agreeableness & .054 & .020 & .172 & .007 \\
\hline Conscientiousness & -.003 & .019 & -.010 & .882 \\
\hline Neuroticism & .007 & .018 & .020 & .715 \\
\hline Openness & -.004 & .017 & -.012 & .836 \\
\hline Support & .013 & .004 & .189 & .004 \\
\hline Physical activity & .009 & .008 & .085 & .273 \\
\hline
\end{tabular}

Cassidy et al. (2014) found that benefit finding grows within a framework of psychological and social resources. However, with significant social and economic changes since the Baby Boomer generation were children, we may be witnessing the emergence of cohort effects in terms of benefit-finding. If a cohort effect does exist in terms of benefit-finding, then it is possible that our focus may be in the wrong place - other factors such as changing parenting techniques, changes in social interactions, or a more individualistic society may have resulted in a greater number of less happy, less resilient people, less able to find benefit in adverse situations. This could possibly explain the unexpected results regarding the higher benefit finding levels found in the older sample. The cross-sectional nature of this study, however, limits the ability to draw any conclusions on whether a cohort effect exists.

Future research could look at these generational effects more closely and also extend the research to cross- cultural analysis. Generational effects no doubt play a part in the health and well-being of individuals through changing environments and social conditions. This is further complicated by the growth of multi-cultural societies and is likely to be differentially distributed across other cultures and societies.

The psychometric properties performed well in this study with good levels of reliability and internal consistency shown and the criteria suggested by Lamping et al. (2002) were clearly met, similar to the original study. When testing for goodness of fit, it was found that allowing reprioritisation to correlate with acceptance and relationships improved the model substantially. This concurred with the original study where these factors were also allowed to correlate and, once again, the GBFS was found to be a good fit for the data when tested on this different, older sample.

The total benefit finding score was significantly positively related to well-being, to agreeableness and to all 
three elements of the support received from friends. Of the Big Five personality types examined, the only significant inverse correlation found was between neuroticism and the acceptance element of benefit finding.

The big surprise, with respect to the psychosocial factors, was that no correlation was found between benefit finding total score and social support from family. This contradicts other recent research (Boehmer, Glickman, Winter, \& Clark, 2014; Brand, Barry, \& Gallagher, 2016; Dunn, Occhipinti, Campbell, Ferguson, \& Chambers, 2011; Măirean, 2016) but does lend support to a recent systematic review which found that evidence for the influence of social support on benefit-finding levels was inconclusive (Pascoe \& Edvardsson, 2013). This finding suggests that, in terms of benefit finding, the perceived support from friends may be more important than that of family members and concurs with Huxhold, Miche, and Schüz (2013) ) who found that, as people age, social interaction with friends becomes more important than with family members, and can serve to protect against some of the negative effects of aging. When considering the findings in this study, several possible limitations must be taken into account. Firstly, benefit-finding is reliant on self-report measures. Since the relationship between self-reported growth and actual growth has been found by some to be small (Frazier et al., 2009) and, in fact, only "fairly accurate" among certain individuals (Gunty et al., 2011, p65), the suggestion that benefitfinding may have illusory aspects (Zoellner \& Maercker, 2006) may need to be investigated further.

Surprisingly, only $9.2 \%$ of the variance in benefitfinding in the current study could be attributed to the significant psychosocial factors investigated. Perhaps other psychosocial factors may be more important. For example, neither religiosity nor ethnicity were considered, yet lower levels of religiosity have been associated with lower levels of benefit-finding (Kleim \& Ehlers, 2009; Sim, Lee, Kim, \& Kim, 2015; Tsai, El-Gabalawy, Sledge, Southwick, \& Pietrzak, 2015; Urcuyo, Boyers, Carver, \& Antoni, 2005) and ethnicity may be a potential predictor of post-traumatic growth (Helgeson et al., 2006; Kleim \& Ehlers, 2009).

The cross-sectional nature of this study is perhaps the greatest limitation. Much of the research into benefit finding has been cross-sectional (Helgeson et al., 2006) and can therefore only give a reflection of the situation at a particular moment in time. It does not allow for any interpretation of the relationships found or causal claims, and any suppositions made within this paper are moot until satisfactory longitudinal analysis is conducted.

\section{Conclusion}

This research paper does, however, add to the literature both on benefit-finding and on older adults. It has provided additional support for the use of the GBFS and has demonstrated that it is a reliable measure and a good fit for the data across different populations.

The findings regarding the effect of perceived social support from friends on benefit finding could have useful applied benefits for those involved in the promotion and maintenance of health in older people. Longitudinal research into aging and subjective well-being in later life has found that quality of life is negatively affected over time by depression, functional limitations and low levels of perceived social support (Zaninotto, Falaschetti, \& Sacker, 2009). Subjective well-being is also adversely affected by isolation and loneliness in older adults (Rafnsson, Shankar, \& Steptoe, 2015). Supporting independent living and enhancing the quality of people's social network can help to minimise much of the age effects on quality of life (Zaninotto et al., 2009). The finding that the perceived support from friends appears to have a greater impact on benefit-finding than that from family means that opportunities in the future to improve and maintain older adults' benefit-finding levels may, in fact, be greater. For a variety of reasons, the availability of supportive relatives cannot be relied upon; however, it may be easier for those who are involved with older adults to work instead on ensuring that a wide network of friends and social acquaintances is maintained.

\section{References}

Affleck, G., Tennen, H., Croog, S., \& Levine, S. (1987). Causal attribution, perceived benefits, and morbidity after a heart attack: an 8-year study. Journal of consulting and clinical psychology, 55(1), 29.

Allemand, M., Schaffhuser, K., \& Martin, M. (2015). Long-term correlated change between personality traits and perceived social support in middle adulthood. Personality and Social Psychology Bulletin, 41(3), 420-432.

Baird, B. M., Lucas, R. E., \& Donnellan, M. B. (2010). Life satisfaction across the lifespan: Findings from two nationally representative panel studies. Social indicators research, 99(2), 183-203.

Boehmer, U., Glickman, M., Winter, M., \& Clark, M. A. (2014). Coping and benefit finding among longterm breast cancer survivors of different sexual orientations. Women \& Therapy, 37(3-4), 222-241.

Bower, J. E., Kemeny, M. E., Taylor, S. E., \& Fahey, J. L. (1998). Cognitive processing, discovery of meaning, CD4 decline, and AIDS-related mortality among bereaved HIV-seropositive men. Journal of consulting and clinical psychology, 66(6), 979.

Brand, C., Barry, L., \& Gallagher, S. (2016). Social support mediates the association between benefit finding and quality of life in caregivers. Journal of health psychology, 21(6), 1126-1136.

Cassidy, T., McLaughlin, M., \& Giles, M. (2014). Benefit finding in response to general life stress: measure- 
ment and correlates. Health Psychology and Behavioral Medicine: an Open Access Journal, 2(1), 268-282.

Chopik, W. J., Kim, E. S., \& Smith, J. (2015). Changes in optimism are associated with changes in health over time among older adults. Social psychological and personality science, 6(7), 814-822.

Deary, I. J., Weiss, A., \& Batty, G. D. (2010). Intelligence and personality as predictors of illness and death: How researchers in differential psychology and chronic disease epidemiology are collaborating to understand and address health inequalities. Psychological science in the public interest, 11(2), 53-79.

Department of Health. (2015, August). Healthy and positive ageing initiative: Preliminary report, may $2015 . \quad$ Retrieved from https://www.dcu.ie/sites/default/files/ afu/DOH_Positive_ageing_report.pdf

Diener, E., Oishi, S., \& Lucas, R. E. (2015). National accounts of subjective well-being. American Psychologist, $70(3), 234$.

Dunn, J., Occhipinti, S., Campbell, A., Ferguson, M., \& Chambers, S. K. (2011). Benefit finding after cancer: The role of optimism, intrusive thinking and social environment. Journal of Health Psychology, 16(1), 169-177.

Frazier, P., Tennen, H., Gavian, M., Park, C., Tomich, P., \& Tashiro, T. (2009). Does self-reported posttraumatic growth reflect genuine positive change? Psychological Science, 20(7), 912-919.

Goodwin, R. D., \& Friedman, H. S. (2006). Health status and the five-factor personality traits in a nationally representative sample. Journal of health psychology, 11(5), 643-654.

Gunty, A. L., Frazier, P. A., Tennen, H., Tomich, P., Tashiro, T., \& Park, C. (2011). Moderators of the relation between perceived and actual posttraumatic growth. Psychological Trauma: Theory, Research, Practice, and Policy, 3(1), 61.

Helgeson, V. S., Reynolds, K. A., \& Tomich, P. L. (2006). A meta-analytic review of benefit finding and growth. Journal of consulting and clinical psychology, 74(5), 797.

Hicks, M. M., \& Conner, N. E. (2014). Resilient ageing: a concept analysis. Journal of Advanced Nursing, $70(4), 744-755$.

Honeycutt, J. M., Nasser, K. A., Banner, J. M., Mapp, C. M., \& DuPont, B. W. (2008). Individual differences in catharsis, emotional valence, trauma anxiety, and social networks among hurricane Katrina and Rita victims. Southern Communication Journal, 73(3), 229-242.

Hooper, D., Coughlan, J., \& Mullen, M. (2008). Structural equation modelling: Guidelines for determin- ing model fit. Articles, 2.

Howarter, A. D., \& Bennett, K. K. (2013). Perceived discrimination and health-related quality of life: Testing the reserve capacity model in Hispanic Americans. The Journal of social psychology, 153(1), 62-79.

Huxhold, O., Fiori, K. L., \& Windsor, T. D. (2013). The dynamic interplay of social network characteristics, subjective well-being, and health: The costs and benefits of socio-emotional selectivity. Psychology and Aging, 28(1), 3.

Huxhold, O., Miche, M., \& Schüz, B. (2013). Benefits of having friends in older ages: Differential effects of informal social activities on well-being in middle-aged and older adults. Journals of Gerontology Series B: Psychological Sciences and Social Sciences, 69(3), 366-375.

Jivraj, S., Nazroo, J., Vanhoutte, B., \& Chandola, T. (2014). Aging and subjective well-being in later life. Journals of Gerontology Series B: Psychological Sciences and Social Sciences, 69(6), 930-941.

Kleim, B., \& Ehlers, A. (2009). Evidence for a curvilinear relationship between posttraumatic growth and posttrauma depression and PTSD in assault survivors. Journal of Traumatic Stress: Official Publication of The International Society for Traumatic Stress Studies, 22(1), 45-52.

Kline, R. B., et al. (2005). Principles and practice of structural equation modeling: Methodology in the social sciences (2nd ed.). New York, NY: Guilford Press.

Lamping, D. L., Schroter, S., Marquis, P., Marrel, A., Duprat-Lomon, I., \& Sagnier, P.-P. (2002). The community-acquired pneumonia symptom questionnaire: a new, patient-based outcome measure to evaluate symptoms in patients with communityacquired pneumonia. Chest, 122(3), 920-929.

Lubben, J., Blozik, E., Gillmann, G., Iliffe, S., von Renteln Kruse, W., Beck, J. C., \& Stuck, A. E. (2006). Performance of an abbreviated version of the Lubben Social Network Scale among three European community-dwelling older adult populations. The Gerontologist, 46(4), 503-513.

Lubben, J. E. (1988). Assessing social networks among elderly populations. Family \& Community Health: The Journal of Health Promotion $\&$ Maintenance.

Măirean, C. (2016). Secondary traumatic stress and posttraumatic growth: Social support as a moderator. The Social Science Journal, 53(1), 14-21.

McConkey, R., \& Leavey, G. (2013). Irish attitudes to sexual relationships and people with intellectual disability. British Journal of Learning Disabilities, 41(3), 181-188.

McGregor, B. A., \& Antoni, M. H. (2009). Psychological intervention and health outcomes among women 
treated for breast cancer: a review of stress pathways and biological mediators. Brain, behavior, and immunity, 23(2), 159-166.

McKee, K. J., \& Schüz, B. (2015). Psychosocial factors in healthy ageing. Taylor \& Francis.

Momtaz, Y. A., Haron, S. A., Ibrahim, R., \& Hamid, T. A. (2014). Social embeddedness as a mechanism for linking social cohesion to well-being among older adults: moderating effect of gender. Clinical interventions in aging, 9, 863.

Morrison, V., \& Bennett, P. (2012). An Introduction to Health Psychology (3rd ed.). Essex: Pearson Education Ltd.

Pascoe, L., \& Edvardsson, D. (2013). Benefit finding in cancer: a review of influencing factors and health outcomes. European Journal of Oncology Nursing, $17(6), 760-766$.

Pilkington, R., Taylor, A. W., Hugo, G., \& Wittert, G. (2014). Are baby boomers healthier than generation $\mathrm{x}$ ? a profile of australia's working generations using national health survey data. PloS one, 9(3), e93087.

Poon, C. Y. M., \& Knight, B. G. (2013). Parental emotional support during emerging adulthood and baby boomers' well-being in midlife. International Journal of Behavioral Development, 37 (6), 498-504.

Rafnsson, S. B., Shankar, A., \& Steptoe, A. (2015). Longitudinal influences of social network characteristics on subjective well-being of older adults: findings from the ELSA study. Journal of Aging and Health, 27(5), 919-934.

Rammstedt, B., \& John, O. P. (2007). Measuring personality in one minute or less: A 10-item short version of the Big Five Inventory in English and German. Journal of research in Personality, 41(1), 203-212.

Shakespeare-Finch, J., \& Lurie-Beck, J. (2014). A metaanalytic clarification of the relationship between posttraumatic growth and symptoms of posttraumatic distress disorder. Journal of anxiety disorders, 28(2), 223-229.

Silva, A. G., Queirós, A., Alvarelhão, J., \& Rocha, N. P. (2014). Validity and reliability of the portuguese version of the rapid assessment of physical activity questionnaire. International Journal of Therapy and Rehabilitation, 21(10), 469-474.

Sim, B. Y., Lee, Y. W., Kim, H., \& Kim, S. H. (2015). Post-traumatic growth in stomach cancer survivors: Prevalence, correlates and relationship with healthrelated quality of life. European Journal of Oncology Nursing, 19(3), 230-236.

Smith, S. C., Lamping, D. L., Banerjee, S., Harwood, R., Foley, B., Smith, P., ... others (2005). Measurement of health-related quality of life for people with dementia: development of a new instrument (DEMQOL) and an evaluation of current method- ology. Health Technology Assessment (Winchester, England), 9(10), 1-93.

Stewart-Brown, S., Tennant, A., Tennant, R., Platt, S., Parkinson, J., \& Weich, S. (2009). Internal construct validity of the Warwick-Edinburgh mental well-being scale (WEMWBS): a Rasch analysis using data from the Scottish health education population survey. Health and quality of life outcomes, $7(1), 15$.

Tampubolon, G. (2015). Delineating the third age: joint models of older people's quality of life and attrition in britain 2002-2010. Aging \& mental health, 19(7), $576-583$.

Tennant, R., Hiller, L., Fishwick, R., Platt, S., Joseph, S., Weich, S., ... Stewart-Brown, S. (2007). The warwick-edinburgh mental well-being scale (WEMWBS): development and UK validation. Health and Quality of life Outcomes, 5(1), 63.

Tennen, H., \& Affleck, G. (2002). Benefit-finding and benefit-reminding. Handbook of positive psychology, 1, 584-597.

Topolski, T. D., LoGerfo, J., Patrick, D. L., Williams, B., Walwick, J., \& Patrick, M. A. J. M. B. (2006). Peer reviewed: the Rapid Assessment of Physical Activity (RAPA) among older adults. Preventing chronic disease, 3(4). Retrieved from http://www .cdc.gov/pcd/issues/2006/oct/06_0001.htm

Tsai, J., El-Gabalawy, R., Sledge, W. H., Southwick, S. M., \& Pietrzak, R. H. (2015). Post-traumatic growth among veterans in the USA: results from the national health and resilience in veterans study. Psychological Medicine, 45(1), 165-179.

Twenge, J. M. (2014). Generation me-revised and updated: Why today's young americans are more confident, assertive, entitled-and more miserable than ever before. Simon and Schuster.

Urcuyo, K. R., Boyers, A. E., Carver, C. S., \& Antoni, M. H. (2005). Finding benefit in breast cancer: Relations with personality, coping, and concurrent well-being. Psychology \& Health, 20(2), 175-192.

Vega-López, S., Chavez, A., Farr, K. J., \& Ainsworth, B. E. (2014). Validity and reliability of two brief physical activity questionnaires among Spanishspeaking individuals of Mexican descent. $B M C$ research notes, 7(1), 29.

Weiss, A., Bates, T. C., \& Luciano, M. (2008). Happiness is a personal (ity) thing: The genetics of personality and well-being in a representative sample. Psychological Science, 19(3), 205-210.

Wheatley, A. (2013). Ageing population a ticking timebomb for eu. Irish Examiner. Retrieved from http://www.irishexaminer.com/ireland/ ageing-population-a-ticking-timebomb $-248936 . \mathrm{html}$

WHO. (1947). Constitution of the world health organi- 
sation. Geneva: World Health Organisation.

WHO. (2012). Risk factors of ill health among older people. Retrieved from http://www.euro .who.int/en/health-topics/Life-stages/ healthy-ageing/data-and-statistics/risk -factors-of-ill-health-among-older-people

Wilson, R. S., Krueger, K. R., Arnold, S. E., Schneider, J. A., Kelly, J. F., Barnes, L. L., ... Bennett, D. A. (2007). Loneliness and risk of alzheimer disease. Archives of general psychiatry, 64(2), 234-240.

Zaninotto, P., Falaschetti, E., \& Sacker, A. (2009). Age trajectories of quality of life among older adults: results from the english longitudinal study of ageing. Quality of Life Research, 18(10), 1301-1309.

Zoellner, T., \& Maercker, A. (2006). Posttraumatic growth in clinical psychology - a critical review and introduction of a two component model. Clinical psychology review, 26(5), 626-653. 